\title{
Esophageal varices: TIPS or ligation. What is your final answer?
}

\author{
Eric M Yoshida MD MHSc FRCPC
}

\begin{abstract}
ARTICLE
Pomier-Layrargues G, Villeneuve JP, Deschenes M, Bui B, Perreault P, Fenyves D, Willems B, Marleau D, Bilodeau M, Lafortune M, Dufresne MP. Transjugular intrahepatic portosystemic shunt (TIPS) versus endoscopic variceal ligation in the prevention of variceal rebleeding in patients with cirrhosis: a randomised trial. Gut 2001;48:390-396.
\end{abstract}

\begin{abstract}
ARTICLE SUMMARY
A randomized study was conducted comparing two-year survival and rebleeding rates in patients with liver cirrhosis (Child-Pugh score 12 or less) receiving either transjugular intrahepatic portosystemic shunt (TIPS) $(n=41)$ or serial endoscopic variceal ligation (EVL) $(n=39)$ after initial control of bleeding. Patients with fundal varices were excluded. There was no difference in the two-year rates of survival between the groups (57\% in the TIPS group compared with $56 \%$ in the EVL group), whereas the two-year rebleeding rates were $18.5 \%$ in the TIPS group and $66 \%$ in the EVL group $(\mathrm{P}<0.001)$. No patient who received TIPS suffered uncontrolled bleeding, whereas 11 banded patients had uncontrolled bleeding - of whom eight underwent emergency TIPS and the remaining three died. There was no dif-
\end{abstract}

ference in the rates of encephalopathy at two years between the two groups (44\% in the TIPS group, $47 \%$ in the EVL group). Likewise, the numbers of days spent in hospital were similar between the two groups, both during the index bleed and over two years. The probability of shunt dysfunction in the TIPS group was $73 \%$ at two years.

\section{COMMENTARY}

In the field of gastroenterology/hepatology, there are few emergencies that can be as dramatic and life-threatening as an acute variceal bleed. Historically, these bleeds have been indicators of severe hepatic decompensation and poor prognosis. Likewise, the classic surgical treatment for these bleeds, the emergency portal-caval shunt, was associated with high mortality. Although, in the early years, endoscopic sclerotherapy did not improve short term survival compared with surgery, at least it was less invasive, less expensive and less bloody (1). EVL ('banding') has become first-line endoscopic therapy (2), and TIPS has become the decompressive shunt procedure of choice for emergency bleeds (3) (although elective surgical shunts continue to have a role in selected cases). In the present randomized study, there was no difference in the two-year rate of survival between the two modalities (most died of liver failure not bleeding), but TIPS was clearly superior with regard to rebleeding (48\% absolute and $73 \%$ relative risk reduction).

\footnotetext{
Department of Medicine, University of British Columbia, Vancouver, British Columbia

Correspondence: Dr Eric M Yoshida, 100-2647 Willow Street, Vancouver, British Columbia V5Z 3P1. Telephone 604-875-5371, fax 604-875-5447
} 
Fortunately, uncontrolled early rebleeding in the EVL group was controlled in most cases by emergency TIPS.

Is TIPS the 'final answer' for acute variceal bleeding? The answer depends on clinical judgment and circumstances. Despite the clear advantage of TIPS with regard to rebleeding, most studies have not reported a survival benefit. From the perspective of day-to-day Canadian realities, TIPS is available only in large centres that offer interventional radiology, whereas access to endoscopic modalities is more readily available. Moreover, adjuvant pharmacotherapy, including octreotide (4), for the short term and long term beta-blockers (5) can reduce the risk of rebleeding for endoscopically managed patients, leaving TIPS to those who truly need it.

\section{REFERENCES}

1. Cello JP, Grendell JH, Grass RA, Trunkey DD, Cobb EE, Heilbron DC. Endoscopic sclerotherapy versus portacaval shunt in patients with severe cirrhosis and variceal hemorrhage. N Engl J Med 1984;311:1589-94.

2. Laine L, Cook D. Endoscopic ligation compared with sclerotherapy for threatment of esophageal variceal bleeding. A meta-analysis. Ann Intern Med 1995;123:280-7.

3. Rossle M, Haag K, Ochs A, et al. The transjugular intrahepatic portosystemic stent shunt procedure for variceal bleeding. N Engl J Med 1994;330:165-71.

4. Sung JJY, Chung SCS, Lai CW, et al. Prospective randomized study of effect of octreotide on re-bleeding from oesophageal varices after endoscopic ligation. Lancet 1995;346:1666-9.

5. Lo GH, Lai KH, Cheng JS, et al. Endoscopic variceal ligation plus nadolol and sucralfate compared to ligation alone for the prevention of variceal rebleeding: a prospective randomized trial. Hepatology 2000;32:461-5. 


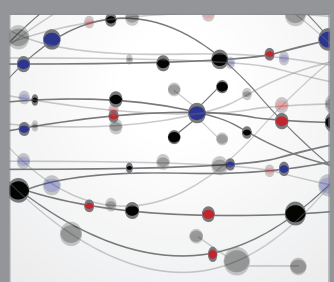

The Scientific World Journal
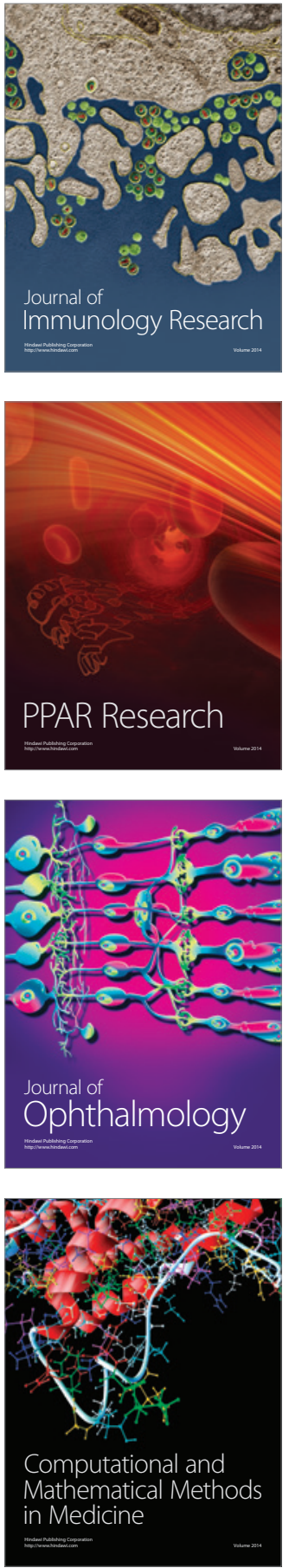

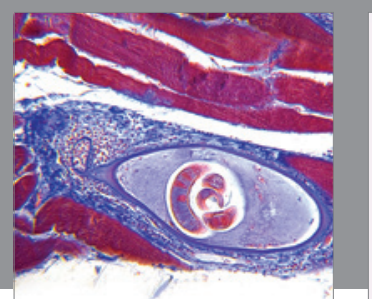

Gastroenterology Research and Practice

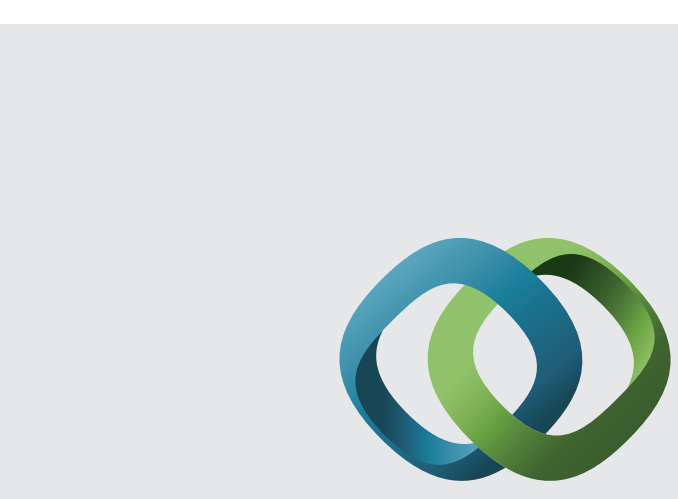

\section{Hindawi}

Submit your manuscripts at

http://www.hindawi.com
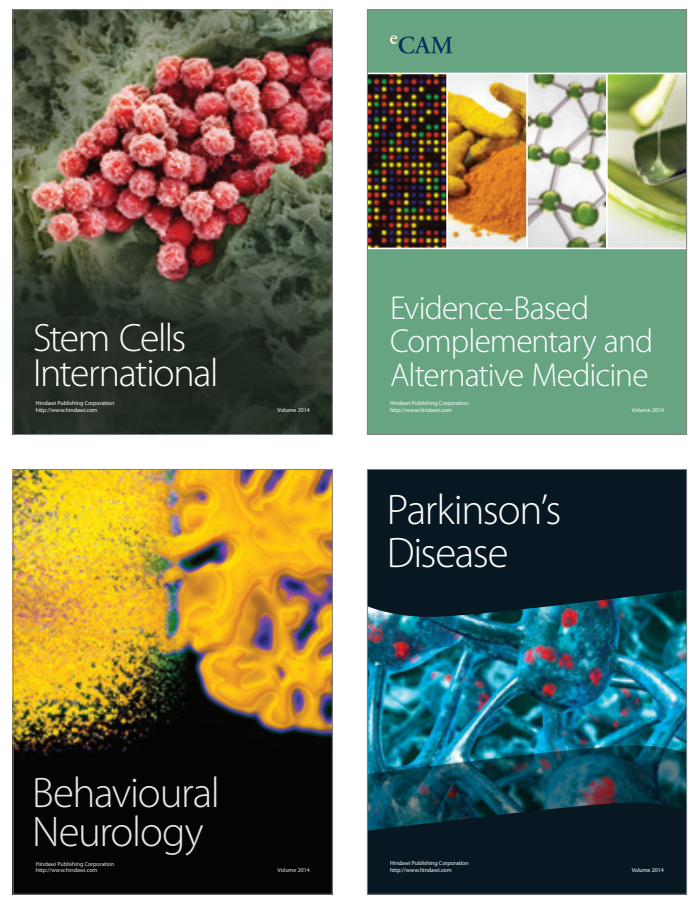
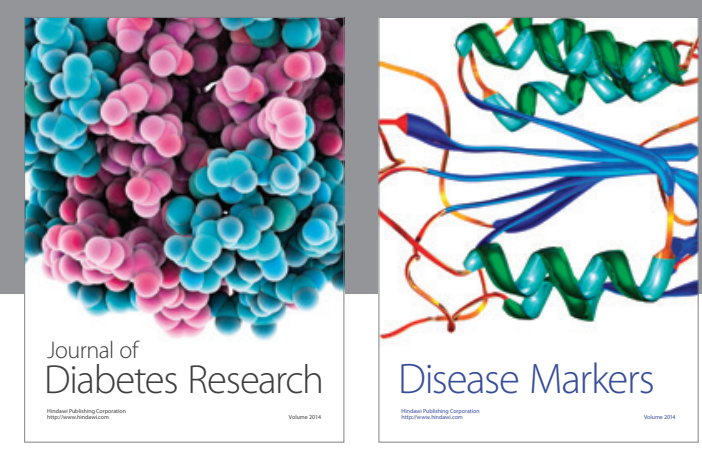

Disease Markers
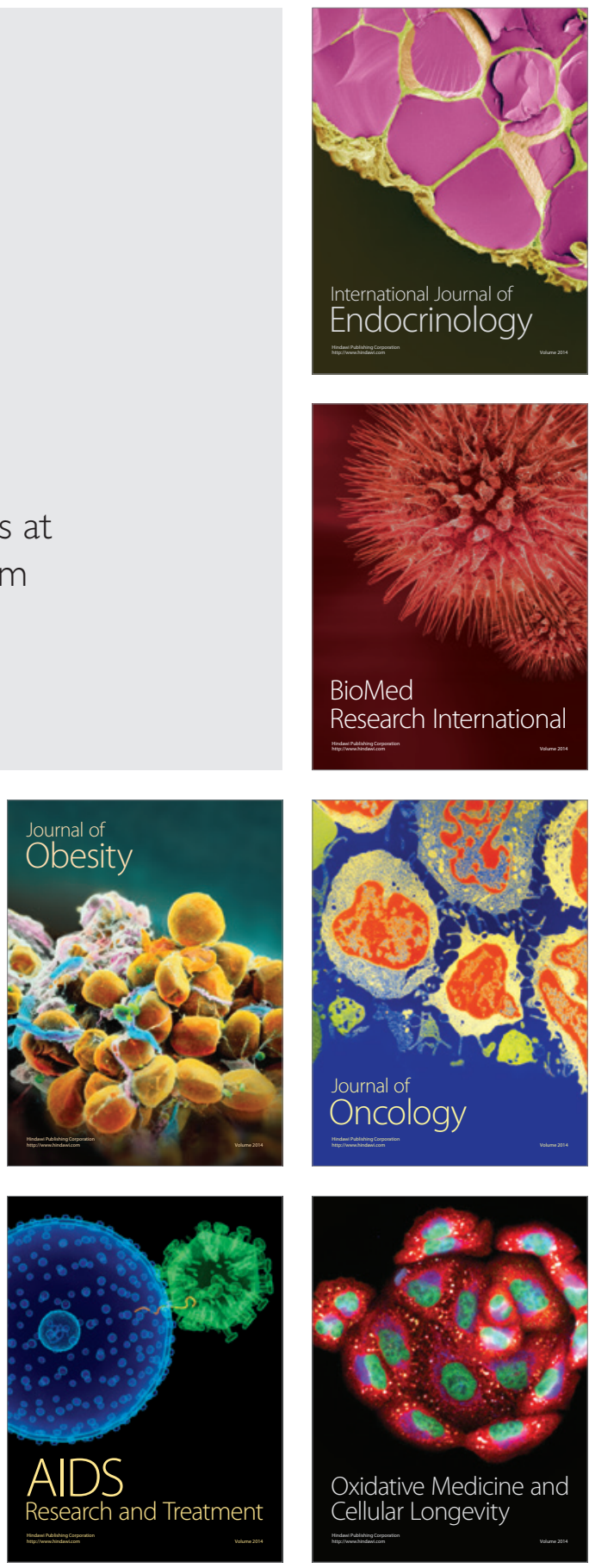